\title{
Trazodone Add-on in COVID-19-related Selective Serotonin Reuptake Inhibitor-resistant Post-traumatic Stress Disorder in Healthcare Workers: Two Case Reports
}

\author{
Domenico De Berardis ${ }^{1,2}$, Michele Fornaro ${ }^{3}$, Antonio Ventriglio ${ }^{4}$, Alessandro Valchera ${ }^{5}$, Federica Vellante ${ }^{2}$, \\ Mauro Pettorruso ${ }^{2}$, Giovanni Martinotti ${ }^{2}$, Silvia Fraticelli ${ }^{2}$, Massimo Di Giannantonio ${ }^{2}$ \\ ${ }^{1}$ National Health Service, Department of Mental Health, Psychiatric Service for Diagnosis and Treatment, Hospital "G. Mazzini", Teramo, \\ ${ }^{2}$ Department of Neurosciences and Imaging, Chair of Psychiatry, University "G. D'Annunzio", Chieti, ${ }^{3}$ Department of Psychiatry, Federico II \\ University, Naples, ${ }^{4}$ Department of Psychiatry, University of Foggia, Foggia, ${ }^{5}$ “Villa S. Giuseppe” Clinic, Hermanas Hospitalarias, Ascoli Piceno, Italy
}

COVID-19 represents a significant stress factor for all people worldwide due to several factors, including quarantine, lockdowns, fear of contagion, deaths, and other traumatic events. However, the healthcare workers (HCWs) have paid the higher price of this pandemic in terms of fatalities, contagions, and psychological well-being. Studies suggest that this particular population is at increased risk of developing a severe post-traumatic stress disorder (PTSD). The early diagnosis and timely treatment of PTSD in HCWs may restore well-being and significantly impact health services functioning, reducing burnout, days spent far from work, disrupted personal and team empowerment, and worse job performances. In the present article, we reported on two cases of HCWs directly involved in the treatment of COVID-19 patients who showed selective serotonin reuptake inhibitor-resistant PTSD, which was successfully treated with extended-release trazodone TRZ Contramid ${ }^{\mathbb{R}}$ add-on.

KEY WORDS: Healthcare workers; COVID-19; PTSD; Serotonin uptake inhibitors; Trazodone; Add-on.

\section{INTRODUCTION}

COVID-19 represents a significant stress factor for all people worldwide $[1,2]$. However, healthcare workers (HCWs) paid the higher price of this pandemic in terms of deaths, contagions, and psychological well-being [3]. The trauma-related stress symptoms in $\mathrm{HCWs}$ are common [4], and several studies investigated the impact of posttraumatic stress on HCWs [5], suggesting that they are at high risk of developing post-traumatic stress disorder (PTSD), adjustment disorders, and other trauma-related disorders $[6,7]$.

PTSD is a severe psychiatric disorder $[8,9]$ and is partic-

Received: November 11, 2020 / Revised: February 6, 2021 Accepted: February 19, 2021

Address for correspondence: Domenico De Berardis Department of Mental Health, Psychiatric Service for Diagnosis and Treatment, Hospital "G. Mazzini”, ASL 4 Teramo, p.zza Italia 1, Teramo 64100, Italia

E-mail: domenico.deberardis@aslteramo.it ORCID: https://orcid.org/0000-0003-4415-5058 ularly insidious in HCWs as, and surprisingly, they are reluctant to seek help [10]. Moreover, during the pandemic, HCWs experienced significantly great fear, ongoing arousal symptoms, and job dissatisfaction [11]. The selective serotonin reuptake inhibitors (SSRIs) are the gold standard in the pharmacological treatment of PTSD patients, but they sometimes do not respond to SSRIs [12].

Trazodone (TRZ) is a different class of antidepressants (serotonin-2 antagonist/reuptake inhibitors), approved for the treatment of major depression [13]. It is somewhat useful in treating PTSD, but the evidence is minimal $[14,15]$. TRZ selectively inhibits neuronal reuptake of serotonin and is an antagonist of $5-\mathrm{HT}_{2 \mathrm{~A}}$. Other TRZ actions include antagonism at several different receptors, including $5-\mathrm{HT}_{2 \mathrm{~B}}, 5-\mathrm{HT}_{2 \mathrm{C}}$, adrenergic $\alpha 1$, and partial agonism at 5-HT1A [16]. TRZ Contramid ${ }^{\mathbb{R}}$ (Angelini, Rome, Italy) once-a-day is an extended-release, once-daily formulation of TRZ, designed to optimize antidepressant action with the anxiolytic/hypnoregulation effect $[16,17]$.

We reported, following the CARE (for CAse REports)

(c) This is an Open-Access article distributed under the terms of the Creative Commons Attribution Non-Commercial License (http://creativecommons.org/licenses/by-nc/4.0) which permits unrestricted non-commercial use, distribution, and reproduction in any medium, provided the original work is properly cited. 
guidelines [18], two cases of HCWs involved in treating COVID-19 patients who showed SSRI-resistant PTSD, which was treated with TRZ Contramid ${ }^{\circledR}$ add-on. We followed the CARE guidelines

\section{CASE}

\section{Case 1}

\section{Symptoms}

A 33-year-old male nurse with no personal or family history of mental illness requested help from an outpatient facility in Teramo (Italy). He worked in an Intensive Therapy Unit and developed symptoms highly suggestive of PTSD. He reported hyperarousal, the feeling to be detached from his life and loved ones, avoiding trauma-related symptoms (the patient did not work anymore as it was on sick leave), hopelessness and depressive symptoms, re-experiencing of traumatic experiences, and disturbing nightmares regarding the deaths he saw and to be infected and intubated. He took escitalopram (ESC) $20 \mathrm{mg}$ prescribed by his general practitioner in March 2020 with partial benefits on hopelessness and depressive symptoms and lower hyper-arousal and detachment. However, especially the nightmares were reported very disturbing, with frequent awakenings that disrupted his sleep.

\section{Diagnosis}

We made a diagnosis of PTSD confirmed by the MiniInternational Neuropsychiatric Interview [19], and the Davidson Trauma Scale (DTS) yielded a frequency score (FS) of 49, a severity score (SS) of 57, and a total score (TS) of 107.

\section{Interventions}

He refused to introduce a benzodiazepine to improve sleep and the introduction of melatonin as he took it without benefits. We suggested adding a low dosage of TRZ Contramid $^{\circledR}$ once-a-day (75 mg at bedtime) to strengthen ESC's response and improve sleep, and the patient accepted. After one week of treatment, he reported improved sleep quality and a slight reduction in DTS scores ( $F S=40, \mathrm{SS}=$ 39 , TS $=79$ ). After the other three weeks of treatment, the patient told us that the nightmares were almost disappeared and the symptoms were significantly relieved (DTS: $F S=20, S S=21, T S=41$ ). We decided to keep the
TRZ at $75 \mathrm{mg} /$ day, lowering ESC to $10 \mathrm{mg} /$ day. After two weeks of continuous improvement, the patient showed a remarkable response without adverse effects (DTS: FS $=0$, $\mathrm{SS}=11$, TS $=23$ ), with the disappearance of nightmares. He decided to go back to work.

\section{Outcomes}

The last visit was carried out in October 2020, and the patient was fully remitted (DTS: $\mathrm{FS}=3, \mathrm{SS}=5, \mathrm{TS}=8$ ). $\mathrm{He}$ took ESC $10 \mathrm{mg} /$ day and TRZ Contramid ${ }^{R} 75 \mathrm{mg} /$ day without adverse effects. His remarkable comment was that "when my nightmares began to be less invasive, I felt better." No adverse effects were reported, and he agreed to begin a trauma-focused cognitive-behavioral therapy (TF-CBT).

\section{Case 2}

\section{Symptoms}

A 44-year-old female nurse with no personal or family history of mental illness requested help from an outpatient facility in a Central Italy region. She worked in an Infectious Disease Unit and sought our assistance due to the development of PTSD symptoms. She experienced an intense burnout feeling due to depressive symptoms, fear of contagion of self and beloved ones, anhedonia, hyperarousal, and unwanted and intrusive thoughts about the COVID patients who saw. She avoided places that reminded her of the COVID, and she was absent from work for almost 40 days before our first visit. Moreover, despite being at home, she was having disturbing nightmares concerning the virus, the contagion, and the sensation to be in a biocontainment unit and suffocate, which caused her to miss many hours of sleep each night. She reported that repeated sudden awakenings during the night had also disturbed her husband and son's sleep, and she preferred to sleep on the couch. She was taking low paroxetine (PAR) dosage $(20 \mathrm{mg}$ ) prescribed by a private psychiatrist in April 2020, without benefits.

\section{Diagnosis}

At the time of our first assessment, we diagnosed PTSD that was confirmed by the administration of the MiniInternational Neuropsychiatric Interview [19], and the DTS scores were remarkably high ( $F S=59, \mathrm{SS}=61$, TS $=$ 120). She told us that "...sleeping is a trouble for me as 
nightmares of being sick and suffocate are my main concerns".

\section{Interventions}

We prescribed mirtazapine $15 \mathrm{mg}$ at bedtime and increased PAR to $40 \mathrm{mg} /$ day. However, after two weeks, the patient dropped mirtazapine due to excessive drowsiness and no benefits over nightmares. She continued to take PAR due to a slight effect on depressive symptoms. Her DTS scores were still high ( $F S=51, S S=52, T S=103$ ), and the nightmares were always compelling. However, she refused to add other medication, trusting in a positive PAR effect titrated to $40 \mathrm{mg} /$ day. After another three weeks of no improvement, the patient again asked us for help, and we prescribed TRZ Contramid ${ }^{\mathbb{R}} 75 \mathrm{mg}$ at bedtime, in addition to PAR. She did not report substantial benefits after one week of combined therapy except for a slight improvement in sleep quality. We decided to increase the TRZ dosage to $150 \mathrm{mg}$. After two weeks, she reported a slight improvement in overall PTSD scores on DTS ( $F S=40, S S=32, T S=72$ ). We lowered PAR to 20 $\mathrm{mg} /$ day and continued with TRZ $150 \mathrm{mg}$. After one month of continuous improvement (mostly on sleep and nightmares), she achieved a response (DTS: $\mathrm{FS}=26, \mathrm{SS}=23$, $\mathrm{TS}=49$ ) without adverse effects. After another month, she decided to go back to work and begin psychological counseling (DTS: $F S=12, S S=10, T S=22$ ).

\section{Outcomes}

The last visit was made in October 2020, and she was fully remitted (DTS: $F S=7, S S=6, T S=13$ ), always taking PAR $20 \mathrm{mg}$ and TRZ Contramid ${ }^{\circledR} 150 \mathrm{mg}$. No adverse effects were observed. Similar to Case 1 , she told us that “... improvement of sleep and disappearance of nightmare was the game changer!".

Both patients gave us a written informed consent to report their cases.

\section{DISCUSSION}

To date, this is the first paper that reported a successful combination of SSRIs/TRZ Contramid ${ }^{\mathbb{R}}$ therapy in the treatment of SSRI-resistant PTSD in HCWs. In both cases, we diagnosed PTSD with a clinical assessment and HCWs interviews as routinely made in the "real world" clinical practice, with the help of the Mini-International Neuro- psychiatric Interview and the DTS to quantify the severity of symptoms and monitor follow-up.

SSRIs and TF-CBT are the first-line treatments of PTSD, but several patients may remain symptomatic and functionally impaired despite treatments $[20,21]$. Therefore, targeting these symptoms is critical in the beneficial treatment of resistant PTSD [22]. Most specialists approve that PTSD and obstinate nightmares should not be regarded as treatment-refractory unless it has had an adequate prazosin trial [23-25]. However, prazosin, an $\alpha 1$-blocker, isn't available in Italy, and we considered an alternative strategy.

Low dose TRZ Contramid $^{\mathbb{R}}$ (i.e., dosages $\leq 150 \mathrm{mg} /$ day) acts at $5-\mathrm{HT}_{2 \mathrm{~A}}, \mathrm{H} 1$, and, primarily, $\alpha 1$ receptors, working also as a sedative-hypnotic medication [26]. The $\alpha 1$ receptors' action may explain the positive effect of TRZ add-on in the two cases. This action may somewhat resemble that of prazosin, improving nightmares, and leading to symptoms remission [27]. In both case reports, nightmares were the most disturbing and marked symptoms, which might explain TRZ's beneficial action. Moreover, TRZ has an overall beneficial effect on sleep architecture than SSRI, restoring slow-wave sleep, improving REM sleep, and improving sleep continuity [28]. This may also explain the positive results seen. The presence and severity of sleep disturbances in PTSD are associated with increased risk of substance abuse, more severe daytime PTSD symptoms, increased risk of suicidal ideation, and worse quality of life and subjective well-being [29]. The treatment with a drug as TRZ that targets sleep disturbances might be crucial for better PTSD treatment outcomes. This action of TRZ is essential because several studies showed that benzodiazepines (BZDs) should be considered relatively contraindicated for patients with PTSD or recent trauma [30,31]. Moreover, persons with PTSD may quickly develop substance-related problems, particularly with BZDs and z-pills, and, therefore, their administration should be avoided [32].

Moreover, the dosage of TRZ Contramid ${ }^{\circledR} 75-150 \mathrm{mg}$ may further enhance SSRIs' action on the dorsolateral prefrontal cortex (dIPFC), dorsomedial PFC, ventrolateral PFC (vIPFC), and the ventromedial PFC, brain regions implicated in PTSD pathophysiology, restoring serotonin and noradrenaline imbalance [33]. It is possible to hypothesize that TRZ Contramid ${ }^{\mathbb{R}}$, due to extended-release, may also effectively inhibit the $5-\mathrm{HT}_{2 \mathrm{~A}}$ and $5-\mathrm{HT}_{2} \mathrm{C}$ receptors and block the serotonin transporter than immedi- 
ate release TRZ formulations [34]: this may further explain the SSRIs potentiation seen in described cases.

It is also unlikely that a pharmacokinetic interaction may explain the SSRI/TRZ combination's positive effect. TRZ is extensively metabolized by cytochrome P450 3A4, whereas ESC is a negligible inhibitor of the same cytochrome, and PAR is mainly metabolized by CYP2D6 [35].

In conclusion, these cases highlight the TRZ Contramid ${ }^{\mathbb{R}}$ potential benefit when associated with SSRIs. Subjects with more prominent sleep disturbances and nightmares may be more susceptible to achieve a good response with this combination, but further studies are needed. Moreover, we firmly believe a global effort must be made to timely diagnose stress-related disorders and PTSD in HCWs [36-39]. Improving the well-being and preventing psychiatric disorders in such persons implicitly means improving healthcare systems worldwide $[40,41]$. Besides, COVID-19 reducing stigma strategies must be another concomitant priority to not repeat the errors made with HIV infection [42].

\section{- Conflicts of Interest}

No potential conflict of interest relevant to this article was reported.

\section{Author Contributions}

Conceptualization: Domenico De Berardis, Michele Fornaro, Antonio Ventriglio, Federica Vellante. Cases acquisition and description: Domenico De Berardis, Federica Vellante, Antonio Ventriglio. Cases discussion: Domenico De Berardis, Michele Fornaro, Antonio Ventriglio, Alessandro Valchera, Federica Vellante, Mauro Pettorruso, Giovanni Martinotti, Silvia Fraticelli, Massimo Di Giannantonio. Supervision: Mauro Pettorruso, Giovanni Martinotti, Silvia Fraticelli, Massimo Di Giannantonio. Writing-original draft: Domenico De Berardis, Michele Fornaro, Antonio Ventriglio, Alessandro Valchera, Federica Vellante. Writing-review \& editing: Domenico De Berardis, Mauro Pettorruso, Giovanni Martinotti, Silvia Fraticelli, Massimo Di Giannantonio.

\section{口 ORCID}

Domenico De Berardis

https://orcid.org/0000-0003-4415-5058

Michele Fornaro https://orcid.org/0000-0002-9647-0853

Antonio Ventriglio https://orcid.org/0000-0002-3934-7007
Federica Vellante https://orcid.org/0000-0002-4844-5688

Mauro Pettorruso https://orcid.org/0000-0002-4164-3040

Giovanni Martinotti

https://orcid.org/0000-0002-7292-2341

Massimo Di Giannantonio

https://orcid.org/0000-0001-9681-8058

\section{REFERENCES}

1. Giallonardo V, Sampogna G, Del Vecchio V, Luciano M, Albert $\mathrm{U}$, Carmassi $\mathrm{C}$, et al. The impact of quarantine and physical distancing following COVID-19 on mental health: study protocol of a multicentric Italian population trial. Front Psychiatry 2020;11:533.

2. Adiukwu F, Bytyçi DG, Hayek SE, Gonzalez-Diaz JM, Larnaout A, Grandinetti P, et al. Global perspective and ways to combat stigma associated with COVID-19. Indian J Psychol Med 2020;42:569-574.

3. Horesh $\mathrm{D}$, Brown AD. Traumatic stress in the age of COVID-19: a call to close critical gaps and adapt to new realities. Psychol Trauma 2020;12:331-335.

4. Raudenská J, Steinerová V, Javůrková A, Urits I, Kaye AD, Viswanath $\mathrm{O}$, et al. Occupational burnout syndrome and post-traumatic stress among healthcare professionals during the novel coronavirus disease 2019 (COVID-19) pandemic. Best Pract Res Clin Anaesthesiol 2020;34:553-560.

5. Carmassi C, Foghi C, Dell'Oste V, Cordone A, Bertelloni CA, Bui $\mathrm{E}$, et al. PTSD symptoms in healthcare workers facing the three coronavirus outbreaks: what can we expect after the COVID-19 pandemic. Psychiatry Res 2020;292:113312.

6. Haghgoshayie E, Hasanpoor E. Healthcare workers are at risk of acute or post-traumatic stress and psychological distress during emerging virus outbreaks. Evid Based Nurs 2020. doi: 10.1136/ebnurs-2020-103317. [Epub ahead of print]

7. Maunder R. The experience of the 2003 SARS outbreak as a traumatic stress among frontline healthcare workers in Toronto: lessons learned. Philos Trans R Soc Lond B Biol Sci 2004; 359:1117-1125.

8. Kishimoto A, Goto Y, Hashimoto K. Post-traumatic stress disorder symptoms in a female patient following repeated teasing: treatment with gabapentin and lamotrigine and the possible role of sensitization. Clin Psychopharmacol Neurosci 2014; 12:240-242.

9. Bae SM, Hyun MH, Lee SH. Comparison of memory function and MMPI-2 profile between post-traumatic stress disorder and adjustment disorder after a traffic accident. Clin Psychopharmacol Neurosci 2014;12:41-47.

10. Shi L, Wang L, Jia X, Li Z, Mu H, Liu X, et al. Prevalence and correlates of symptoms of post-traumatic stress disorder among Chinese healthcare workers exposed to physical violence: a cross-sectional study. BMJ Open 2017;7:e016810.

11. Carmassi C, Cerveri G, Bui E, Gesi C, Dell'Osso L. Defining effective strategies to prevent post-traumatic stress in healthcare 
emergency workers facing the COVID-19 pandemic in Italy. CNS Spectr 2020. doi: 10.1017/S1092852920001637. [Epub ahead of print]

12. Sutherland ME. Identifying treatment-resistant PTSD. Nat Hum Behav 2019;3:549.

13. Cuomo A, Fiorentini A, Vampini C, Fagiolini A. [Personalized medicine with extended-release trazodone and/or once-a-day trazodone: from research trials to clinical practice]. Riv Psichiatr 2020;55:255-261. Italian.

14. Warner MD, Dorn MR, Peabody CA. Survey on the usefulness of trazodone in patients with PTSD with insomnia or nightmares. Pharmacopsychiatry 2001;34:128-131.

15. Detweiler MB, Pagadala B, Candelario J, Boyle JS, Detweiler JG, Lutgens BW. Treatment of post-traumatic stress disorder nightmares at a veterans affairs medical center. J Clin Med 2016;5:117.

16. Goracci A, Forgione RN, De Giorgi R, Coluccia A, Cuomo A, Fagiolini A. Practical guidance for prescribing trazodone extended-release in major depression. Expert Opin Pharmacother 2016:17:433-441.

17. Cuomo A, Ballerini A, Bruni AC, Decina P, Di Sciascio G, Fiorentini A, et al. Clinical guidance for the use of trazodone in major depressive disorder and concomitant conditions: pharmacology and clinical practice. Riv Psichiatr 2019;54. 137-149.

18. Riley DS, Barber MS, Kienle GS, Aronson JK, von SchoenAngerer $\mathrm{T}$, Tugwell $\mathrm{P}$, et al. CARE guidelines for case reports: explanation and elaboration document. / Clin Epidemiol 2017;89:218-235.

19. Pettersson A, Modin S, Wahlström R, Af Winklerfelt Hammarberg S, Krakau I. The Mini-Internationa/ Neuropsychiatric Interview is useful and well accepted as part of the clinical assessment for depression and anxiety in primary care: a mixed-methods study. BMC Fam Pract 2018;19:19.

20. López CM, Lancaster CL, Wilkerson A, Gros DF, Ruggiero KJ, Acierno R. Residual insomnia and nightmares postintervention symptom reduction among veterans receiving treatment for Comorbid PTSD and depressive symptoms. Behav Ther 2019; 50:910-923.

21. De Berardis D, Vellante F, Fornaro M, Anastasia A, Olivieri L, Rapini $\mathrm{G}$, et al. Alexithymia, suicide ideation, affective temperaments and homocysteine levels in drug naive patients with post-traumatic stress disorder: an exploratory study in the everyday 'real world' clinical practice. Int I Psychiatry Clin Pract 2020;24:83-87.

22. De Berardis D, Marini S, Serroni N, lasevoli F, Tomasetti C, de Bartolomeis A, et al. Targeting the noradrenergic system in posttraumatic stress disorder: a systematic review and metaanalysis of prazosin trials. Curr Drug Targets 2015;16:10941106

23. Reist C, Streja E, Tang CC, Shapiro B, Mintz J, Hollifield M. Prazosin for treatment of post-traumatic stress disorder: a systematic review and meta-analysis. CNS Spectr 2020. doi:
10.1017/S1092852920001121. [Epub ahead of print]

24. Maguire PA, Looi JC. Reappraising prazosin for night-time symptoms in post-traumatic stress disorder. Aust $N Z$ J Psychiatry 2020;54:848-849.

25. Ketenci S, Acet NG, Sarıdoğan GE, Aydın B, Cabadak H, Gören MZ. The neurochemical effects of prazosin treatment on fear circuitry in a rat traumatic stress model. Clin Psychopharmacol Neurosci 2020;18:219-230.

26. Vgontzas AN, Puzino K, Fernandez-Mendoza J, Krishnamurthy VB, Basta M, Bixler EO. Effects of trazodone versus cognitive behavioral therapy in the insomnia with short sleep duration phenotype: a preliminary study. I Clin Sleep Med 2020;16: 2009-2019.

27. Montalbano A, Mlinar B, Bonfiglio F, Polenzani L, Magnani M, Corradetti R. Dual inhibitory action of trazodone on dorsal raphe serotonergic neurons through 5-HT1A receptor partial agonism and $\alpha 1$-adrenoceptor antagonism. PLoS One 2019; 14:e0222855.

28. Wichniak A, Wierzbicka A. [The effects of antidepressants on sleep in depressed patients with particular reference to trazodone in comparison to agomelatine, amitriptyline, doxepin, mianserine and mirtazapine]. Pol Merkur Lekarski 2011;31: 65-70. Polish.

29. Mascarel P, Poirot I, Lardinois M, Debien C, Vaiva G. ISleep disorders and their treatment in post-traumatic stress disorder]. Presse Med 2019:48:1051-1058. French.

30. Guina J, Rossetter SR, DeRHODES BJ, Nahhas RW, Welton RS. Benzodiazepines for PTSD: a systematic review and meta-analysis. J Psychiatr Pract 2015;21:281-303.

31. Gilbert M, Dinh La A, Romulo Delapaz N, Kenneth Hor W, Fan P, Qi X, et al. An emulation of randomized trials of administrating benzodiazepines in PTSD patients for outcomes of suicide-related events. J Clin Med 2020;9:3492.

32. Guina J, Nahhas RW, Goldberg AJ, Farnsworth S. PTSD symptom severities, interpersonal traumas, and benzodiazepines are associated with substance-related problems in trauma patients. J Clin Med 2016;5:70.

33. MacNamara A, Rabinak CA, Kennedy AE, Fitzgerald DA, Liberzon I, Stein MB, et al. Emotion regulatory brain function and SSRI treatment in PTSD: neural correlates and predictors of change. Neuropsychopharmacology 2016;41:611-618.

34. Fagiolini A, Albert U, Ferrando L, Herman E, Muntean C, Pálová E, et al. A randomized, double-blind study comparing the efficacy and safety of trazodone once-a-day and venlafaxine extended-release for the treatment of patients with major depressive disorder. Int Clin Psychopharmacol 2020;35:137146.

35. Hoffelt C, Gross T. A review of significant pharmacokinetic drug interactions with antidepressants and their management. Ment Health Clin 2016;6:35-41.

36. Adiukwu F, Orsolini L, Gashi Bytyçi D, El Hayek S, GonzalezDiaz JM, Larnaout A, et al. COVID-19 mental health care toolkit: an international collaborative effort by Early Career 
Psychiatrists section. Gen Psychiatr 2020;33:e100270.

37. Ransing R, Ramalho R, Orsolini L, Adiukwu F, Gonzalez-Diaz JM, Larnaout A, et al. Can COVID-19 related mental health issues be measured? Brain Behav Immun 2020;88:32-34.

38. Saracoglu KT, Simsek T, Kahraman S, Bombaci E, Sezen Ö, Saracoglu A, et al. The psychological impact of COVID-19 disease is more severe on intensive care unit healthcare providers: a cross-sectional study. Clin Psychopharmacol Neurosci 2020;18:607-615.

39. Kim JW, Stewart R, Kang SJ, Jung SI, Kim SW, Kim JM. Telephone based Interventions for Psychological Problems in Hospital Isolated Patients with COVID-19. Clin Psychopharmacol Neurosci 2020;18:616-620.
40. Pereira-Sanchez V, Adiukwu F, El Hayek S, Bytyçi DG, Gonzalez-Diaz JM, Kundadak GK, et al. COVID-19 effect on mental health: patients and workforce. Lancet Psychiatry 2020;7:e29-e30.

41. Ransing R, Adiukwu F, Pereira-Sanchez V, Ramalho R, Orsolini L, Teixeira ALS, et al. Mental health interventions during the COVID-19 pandemic: a conceptual framework by early career psychiatrists. Asian J Psychiatr 2020;51:102085.

42. Ransing R, Ramalho R, de Filippis R, Ojeahere MI, Karaliuniene $\mathrm{R}$, Orsolini $\mathrm{L}$, et al. Infectious disease outbreak related stigma and discrimination during the COVID-19 pandemic: drivers, facilitators, manifestations, and outcomes across the world. Brain Behav Immun 2020;89:555-558. 